\title{
Argument hierarchy and other factors determining argument realization
}

\author{
Dieter Wunderlich (Düsseldorf) \\ Conference on Semantic Role Universals (Leipzig. 5. Dec. 2002)
}

\section{Introduction}

Most, if not all argument linking systems derive from generalizations based on agentive transitive verbs. Cross-linguistically, the creation of relational predicates (encoded in basic transitive verbs) is governed by a universal principle: the higher argument is more agentlike and more salient in terms of person, animacy and specificity than the lower one. Since also non-agentive types of verbs are possible, every language has to make certain generalizations for these types of verbs, and since variation in the type of argument values is possible, every language has to make certain generalizations for non-canonical distributions of argument values. Moreover, every language has to set off the set of transitive verbs from intransitive ones, for instance, to reflect conditions under which transitive verbs are reduced and, vice versa, intransitive verbs are enriched. Finally, every language has to make certain provisos of how to deal with 3-place predicates (to be encoded in ditransitive verbs or verb serialization), and to supply with further means of complex predicate formation.

The central function of agentive transitive verbs in a grammar is also reflected in the theories concerned with argument linking. Several theories, including classical generative grammar, only accept two true ('structural') arguments of a verb, designated by abstract case ('accusative' vs. 'nominative') or grammatical function ('object' vs. 'subject'). Semantically oriented theories distinguish between proto-agent and proto-patient roles (Dowty 1991), while Role and Reference Grammar (RRG; Van Valin 1993) mediates between semantic and structural properties by the two macroroles 'actor' and 'undergoer'. It is generally accepted that agents are more salient than patients, hence better candidates for topic, whereas patients are better candidates for focus.

Prototypical transitive verbs ${ }^{1}$

\begin{tabular}{|c|c|c|c|}
\hline & $\lambda y$ & $\lambda \mathrm{x}$ & $\operatorname{VERB}(\mathrm{x}, \mathrm{y})$ \\
\hline abstract case & accusative & nominative & \\
\hline grammatical function & object & subject & \\
\hline protoroles & proto-patient & proto-agent & \\
\hline macroroles & undergoer & actor & \\
\hline $\begin{array}{l}\text { natural distribution of salience } \\
\text { (person, animacy, specificity) }\end{array}$ & less salient & more salient & \\
\hline natural candidate for & focus & topic & \\
\hline
\end{tabular}

Because of their design properties, all theories capture agentive transitive verbs sufficiently (in this respect they are compatible), but as soon as it comes to other types of verbs, they

1 The notation $\lambda \mathrm{y} \lambda \mathrm{x} \operatorname{VERB}(\mathrm{x}, \mathrm{y})$ (as well as its alternative $\lambda \mathrm{y} \lambda \mathrm{x} \operatorname{VERB}(\mathrm{y})(\mathrm{x}))$ indicates that $\mathrm{x}$ is the higher argument and $y$ the lower argument (which 'more narrowly' belongs to the verb). The higher argument is also called '(logical) subject', and the lower argument is called '(logical) object'. These notions are invariant cross-linguistically, whereas all morphosyntactic notions such as 'grammatical subject', 'direct object' or 'nominative' are language-dependent. Throughout this paper, the event argument of a verb is neglected. 
largely differ from each other. The crucial role of ditransitive verbs for a theory of grammar has been recognized only recently. One remarkable point is that ditransitive verbs in a language with positional linking (like English) behave differently from those in a language with morphological case (like German), as confirmed with data from passive.

(2) a. The woman gave him two books.

He was (sg.) given two books.

b. Die Frau gab ihm zwei Bücher.

Ihm (DAT) wurden (pl.) zwei Bücher gegeben.

In a positional system, the recipient (or 'primary object') becomes syntactic subject in the passive, whereas in a system with morphological case, the theme (or 'direct object') is shifted to nominative in the passive, while the recipient (the 'indirect object') stays in the dative. In any case, the recipient should be considered a medial argument, as reflected by its place in the default word order, among others. This fact can be captured by the assumption of lexical decomposition, claiming that ditransitive verbs are constituted by at least two predicates. $^{2}$

$$
\text { 'give' verbs: } \lambda \mathrm{z} \lambda \mathrm{y} \lambda \mathrm{x}\{\mathrm{ACT}(\mathrm{x}) \& \operatorname{BECOME} \operatorname{POSS}(\mathrm{y}, \mathrm{z})\}
$$

Many theories of grammar have no adequate place for medial arguments. This can be seen if one tries to apply the criteria used in (1) to the recipient of ditransitive verbs.

(4) No place for medial arguments in various linguistic theories

\begin{tabular}{|c|c|c|c|c|}
\hline & $\lambda z$ & $\lambda y$ & $\lambda x$ & $\operatorname{VERB}(\mathrm{x}, \mathrm{y}, \mathrm{z})$ \\
\hline abstract case & accusative & none & nominative & \\
\hline grammatical function & object & $\begin{array}{l}\text { prim. obj/ } \\
\text { indir. obj }\end{array}$ & subject & \\
\hline protoroles & proto-patient & $\begin{array}{c}\text { mixed } \\
\text { (recipient) }\end{array}$ & proto-agent & \\
\hline macroroles & undergoer & none & actor & \\
\hline $\begin{array}{l}\text { natural distribution of } \\
\text { salience (person, animacy, } \\
\text { specificity) }\end{array}$ & less salient & more salient & more salient & \\
\hline natural candidate for & focus & $? ?$ & topic & \\
\hline
\end{tabular}

Not every language allows to express three arguments of a verb structurally, be it in the syntax or in the morphology. But this typological restriction does not mean that the existence of three structural arguments is forbidden in general, which many theories suggest. The concept of argument hierarchy seems to be more fruitful than the concept of abstract case because it gives the possibility to extend the number of structural arguments to more than just two.

A language with morphological case also allows to mark dative in instances where the respective argument is either the lowest or the highest one; there is no similar option for positional languages.

2 Note that ' $\&$ ' is an asymmetric coordination, which means that the predicate to the left commands the predicate to the right. In other words: $\{\mathrm{A} \& \mathrm{~B}\}$ is bracketed as $[\mathrm{A}[\& \mathrm{~B}]]$. Consequently, $\mathrm{x}$ in (3) is higher than both $\mathrm{y}$ and $\mathrm{z}$. 
a. Ich half dem Jungen (DAT).

I helped the boy.

b. Mir (DAT) gefiel das Haus.

I liked the house.

The case patterns $<$ nom,acc $>$, $<$ nom,dat $>$ and $<$ dat,nom $>$ in German ${ }^{3}$ collapse to just a single transitive verb class SVO in English. Lexical marking is a device that can potentially characterize verb classes in a semantic perspective.

Another area in which semantic factors come into play is the basic asymmetry of transitive verbs. As pointed out already, the higher argument of a transitive verb is likely to be more salient than the lower one, in terms of person, animacy or specificity. These circumstances constitute the direct setting; they are reversed in an inverse setting.

(6) Direct and inverse settings of argument values

\begin{tabular}{|c|c|}
\hline direct settings & inverse settings \\
\hline $\begin{array}{l}\lambda \mathrm{y} \quad \lambda \mathrm{x} \quad \operatorname{VERB}(\mathrm{x}, \mathrm{y}) \\
3 \quad 1 \\
\text { I hit him. }\end{array}$ & $\begin{array}{lll}\lambda \mathrm{y} & \lambda \mathrm{x} & \operatorname{VERB}(\mathrm{x}, \mathrm{y}) \\
1 & 3 \\
\text { He hit } & \text { me. }\end{array}$ \\
\hline $\begin{array}{l}\lambda \mathrm{y} \quad \lambda \mathrm{x} \quad \operatorname{VERB}(\mathrm{x}, \mathrm{y}) \\
\text {-anim }+ \text { anim } \\
\text { The people surrounded the reed. }\end{array}$ & $\begin{array}{l}\lambda \mathrm{y} \quad \lambda \mathrm{x} \quad \operatorname{VERB}(\mathrm{x}, \mathrm{y}) \\
+ \text { anim -anim } \\
\text { The reed surrounded the people. }\end{array}$ \\
\hline $\begin{array}{l}\lambda y \quad \lambda x \quad \operatorname{VERB}(\mathrm{x}, \mathrm{y}) \\
-\mathrm{spec} \quad+\operatorname{spec} \\
\text { The man hit someone. }\end{array}$ & $\begin{array}{l}\lambda y \quad \lambda x \quad \operatorname{VERB}(\mathrm{x}, \mathrm{y}) \\
+ \text { spec }- \text { spec } \\
\text { Someone hit the man. }\end{array}$ \\
\hline
\end{tabular}

In order to avoid ambiguity, arguments must be distinguishable, preferably both in the morphology and in the syntax. Most fundamental is the following constraint. ${ }^{4}$

3 Notations such as $<$ nom, acc $>$ characterize the default ordering of arguments in the syntax, which the higher argument to the left. This order is reverse to the ordering of the $\lambda$-abstractors (theta-roles) in semantic representations associated with morphological case, for instance, ACC NOM.

4 This constraint can be violated in certain contexts. Consider the following data from relativization in Welsh (Tallerman 1990:296, 302). Because the basic word order is VSO, the gap in (ia) renders the relative clause ambiguous: the gap can be related to either subject or object. This ambiguity, however, is resolved by consonant mutation in (ii), or by pronominal doubling as in (ib).

(i) a. y bachgen a welodd y ci

the boy COMP saw.3sg the dog

'the boy who saw the dog'

'the boy who the dog saw'

b. y bachgen y gwnaeth y ci ei weld

the boy COMP did.3sg the dog he see

'the boy that the dog saw'

(ii) a. y bachgen a welodd gi

the boy COMP saw.3sg dog (+MUT)

'the boy who saw a dog'

b. y bachgen a welodd ci

the boy COMP saw.3sg $\operatorname{dog}(-$ MUT)

'the boy who a dog saw' 
Avoid converse settings to be identically marked.

There are several ways to comply with this requirement: by different positions (as in a SVO language), by different sets of morphemes (such as $m e$ vs. $I$ ), by different morphological cases (accusative vs. nominative), by different agreement patterns, or other means. One, under cognitive aspects rather economic, device is that only particular kinds of inverse settings are marked (for instance, by ergative or accusative), while the corresponding direct settings are not. Such a split device then constitutes another way in which semantic factors enter argument linking.

In summarizing, the factors that determine argument realization involve the following:

1. Argument hierarchy: The argument roles of a predicate are ordered in a unique way.

2. Semantic roles: The argument roles of a predicate can be distinguished by their participation in the 'event' denoted by the verb (such as agent, patient, or experiencer).

3. Sortal (or referential) salience: The arguments of a predicate can be distinguished by their inherent values (such as person, animacy, or specificity).

4. Informational salience: The arguments of a predicate can be distinguished by their informational status (such as topic and focus).

As a matter of fact, informational salience is nearly independent of semantic features of the verb, and thus cannot constitute an efficient argument linking device by itself, but it can be imposed on other systems. Regarding the observation that objects are more natural candidates for focus than subjects, it is interesting to note that the majority of Mayan languages developed an agent focus morpheme, which signals focus for the higher argument (Aissen 1999a, Stiebels 2003), while some Bantu languages developed an antifocus morpheme, which blocks focus for the lower argument (Kimenyi 1980, Morimoto 2002). These facts are expected, while the reverse circumstances (a patient focus morpheme, or a morpheme that blocks agents from focus) are highly unexpected.

Sortal values often depend on the semantic content of a verb, thus, sortal salience can effectively distinguish the arguments for certain semantic classes of verbs. Sortal salience is a dominant factor in the Algonquian languages, where it is encoded both in the stems and in the morphology. The following examples are taken from Potowatomi (Hockett 1948).

(8) Sortal salience encoded in stems
a. Inanimate objects: n-wapt-an
'I see it.'
1 -see-
b. Animate objects: n-wapm-a
1 -see-
'I see him.'

(9) Sortal salience encoded in inverse morphology
a. Direct marker:
k-wapm- $\boldsymbol{a}$-wa
'You(pl) see him.'
2-see-DIR-pl
b. Inverse marker:
k-wapm- $\boldsymbol{k}$-wa
2-see-INV-pl
'He sees you(pl)'

Note that the direct and inverse markers take reference to both the argument hierarchy and the salience hierarchy imposed on the arguments (Wunderlich 1996); an argument linking device that is exclusively based on sortal salience would be rather unexpected.

In the following, I will concentrate on semantic roles in section 2, and argument hierarchy in section 3. I will argue that considering argument hierarchy is a much better device to indicate the role of arguments in a verb than considering their semantic participation. Finally, in section 4 I will be concerned with the two already indicated ways 
in which semantic factors may enter argument linking: by a lexical feature, or by a markedness condition for the argument values.

\section{Semantic roles}

During the recent stages of linguistic theorizing one can observe that every progress in structural generalization is counter-balanced by the rising conviction that grammar is determined semantically. The increasing reference to semantic (thematic) roles is one of these astonishing phenomena. I will argue that, besides of their function of constituting a convenient façon de parler, semantic roles do not play any theoretical function.

Semantic roles always depend on the semantic content of a verb, consequently, there are so many semantic roles as they are verbs, or small semantic classes of verbs. Larger semantic classes could be characterized by more general semantic roles, but still the question remains: how many classes do exist, and how are they defined? More general semantic roles also compete with eventive (aspectual) roles (such as CAUSE and RESULT), which characterize the semantic function of possible subpredicates of a verb.

The following examples (cited from Maling 2001:433) show a collection of ditransitive clauses of Korean in which the putative semantic role of the dative argument is annotated.

(10) Datives in Korean ditransitive constructions, associated with a semantic role

$\begin{array}{lllll}\text { a. Elun-tul-i } & \text { ai-tul-eykey } & \text { senmul-ul } & \begin{array}{l}\text { cwu-ess-ta. } \\ \text { give-PAST-IND }\end{array} & \text { Recipient } \\ \text { adult-pl-NOM } & \text { child-pl-DAT } & \text { gift-ACC } & \text { giv-PAs }\end{array}$

'Adults gave children gifts.'

b. Ku sonyen-un tongmu-eykey phyenci-lul ssu-ess-ta Goal the boy-TOP friend-DAT letter-ACC write-PAST-IND

'The boy wrote (his) friend a letter.'

$\begin{array}{lllll}\text { c. Chinkwu-ka } & \text { na-eykey } & \text { ku muncey-lul } & \text { malha-yess-ta } & \text { Hearer } \\ \text { friend-NOM } & \text { I-DAT } & \text { the problem-ACC } & \text { talk-PAST-IND } & \end{array}$

'(My) friend talked to me about the problem.'

d. Na-nun Tom-eykey cenyek-ul sa-(a)ss-ta.

Beneficiary

I-TOP Tom-DAT dinner-ACC buy-PAST-IND

'I bought Tom dinner.'

e. Na-nun noin-eykey panci-lul sa-(a)ss-ta.

I-TOP old.man-DAT ring-ACC buy-PAST-IND

'I bought a ring from an old man.'
f. Na-nun ku-eykey panci-lul ppayas-ass-ta.
I-TOP he-DAT ring-ACC rob-PAST-IND
'I robbed him of a ring.'

Rather than speculating of whether Goal is a generalization that also captures Source, a much better way is considering the respective dative argument to be medial, either in a representation such as $\{\mathrm{ACT}(\mathrm{x}) \& \operatorname{BECOME} \operatorname{POSS}(\mathrm{y}, \mathrm{z})\}$ or in a representation such as $\{\mathrm{ACT}(\mathrm{x})$ $\&$ BECOME $\neg \operatorname{POSS}(\mathrm{y}, \mathrm{z})\}$. Hence, the generalization is that the dative argument is associated with similar positions in semantic decompositions.

Similarly, there may be individual sentences with a dative argument, being ambiguous between several readings. These readings could be distinguished by using semantic roles, but it is likewise possible to state for each reading some predicate that contributes this reading. The following Albanian examples, adapted from Kallulli (1999: 269f.), illustrate readings induced by non-active morphology and correlated with a higher predicate: 
accidental causation in the aorist (11a-i), and a 'feel like' reading in the present (11b-i). Both sentences also allow readings with POSS, which are generally available for datives.

(11) Datives and non-active morphology in Albanian

a. Ben-it i-u thye

Ben-the.DAT he.DAT-NONACT.AOR break.3sg

i. 'Ben accidentally broke the window.'

dritar-ja.

window-the.NOM

ii. 'Ben's window (suddenly) broke.'

Causer

iii. 'The window broke to Ben.'

Possessor

b. Ben-it i lexo-het

një libër.

Ben-the.DAT he.DAT read-NONACT.PRES.3sg a book.NOM

i. 'Ben feels like reading a book.'

Affectee

ii. 'One can read Ben's book.'

Possessor

iii. 'One can read a book to Ben.'

Beneficiary

The notion of (generalized) semantic roles can be useful only if it exceeds the number of morphosyntactic distinctions of arguments. If transitive verbs can appear with several case patterns, some of them could be considered as lexically marked. The appearance of lexical marking may thus reflect certain (non-canonical) semantic roles, at least in some instances. However, in no way do semantic roles determine whether a verb is lexically marked or not. There are many minimal pairs of nearly synonymous verbs in which only one of these verbs is marked lexically. The following examples are from Icelandic (Maling 2002:3).

(12) Nearly synonymous verbs governing dative (lexically marked) vs. accusative (by canonical realization)

\begin{tabular}{|c|l|}
\hline$<$ nom,dat $>$ & $<$ nom, acc $>$ \\
\hline $\begin{array}{l}\text { hjálpa 'help' } \\
\text { unna 'love' } \\
\text { mæta 'meet' }\end{array}$ & $\begin{array}{l}\text { aðstoða 'help, support' } \\
\text { elska 'love' } \\
\text { hitta 'meet' }\end{array}$ \\
\hline$<$ nom, dat, dat $>$ & $<$ nom, dat, acc $>$ \\
\hline $\begin{array}{l}\text { úthlata 'distribute, hand out' } \\
\text { skila 'return, give back' }\end{array}$ & skammta 'hand out, ration' \\
afhenda 'hand over, give back' \\
\hline
\end{tabular}

One good example in question is the experiencer role. It has been much debated whether experiencers are entities in which certain effects become manifest or rather entities that project their internal states onto an external target. Both alternatives are possible, as shown by transitive verbs from German.

(13) Experiencers in subject or object position
a. Der Sturm ängstigte mich.
'The storm frightened me.'
stimulus - experiencer?
b. Ich fürchtete den Sturm.
NOM ACC
'I feared the storm.'
experiencer-target?
NOM $\quad$ ACC

With an experiencer being the higher role, it is also possible that the experiencer is lexically marked for dative, so that exceptionally the nominative occurs with the lower role.

(14) Lexically marked experiencer role

a. Der Junge mag den Hund. the.NOM boy likes the.ACC dog

experiencer-target
NOM ACC 
b. Dem Jungen gefällt der Hund.

the.DAT boy likes the.NOM dog DAT NOM

Furthermore, experiencers of intransitive verbs can be structurally 'downgraded' by the occurrence of an expletive subject. However, these experiencer verbs can also be inherently reflexive.

(15) Experiencer verbs with an expletive subject (a) or with an inherent reflexive (b).

a. Ihn ekelte es (vor Spinnen).

he.ACC disgusted it (at spiders)

'He was disgusted (at spiders).'

b. Er ekelte sich (vor Spinnen).

he.NOM disgusted himself (at spiders)

'He was disgusted (at spiders).'

Obviously, a language such as German has no general solution of how to handle experiencers grammatically. As many other languages, German developed some structural generalizations for the realization of arguments, including certain types of impersonal constructions, and transferred these structural means historically, not taking reference to individual semantic types of verbs. Thus, if individual types are concerned, several options are available. In the case of 2-place experiencer verbs of German, the best we can say it that experiencers are realized by nominative or dative as the higher argument, otherwise by accusative, depending on further factors, ${ }^{5}$ however, dative subjects overwhelmingly are experiencers.

The concept of semantic role becomes problematic with stative verbs, for which any dynamic identification of roles must fail, ${ }^{6}$ and it breaks down with symmetric verbs, which, by definition, allow each argument in each position. There are always some classes of verbs for which semantic roles cannot predict argument linking

(16) Stative verbs
a. The box contains apples.
container content
b. Apples fill the box.
content container
c. A wall surrounds the garden.
surrounder surrounded

(17) Symmetric verbs
a. Peter and Erna met (each other).
b. Peter met Erna.
c. Erna met Peter.
Both are targets

Another field in which the concept of semantic roles would have to prove useful is the formation of complex predicates. Causatives add a causer, affectives add an experiencer, and assistives add an assistant in higher position (thereby downgrading the former agent to a causee or assistee), while applicatives add either a beneficiary, an instrumental or a locative in lower position. Similarly, resultatives add an object on which the result becomes manifest

5 As Primus and her collaborators (Klein \& Kutscher 2002) have shown, the choice between these structural options does not depend on a finer semantic classification of experiencers, but rather results from historical facts, namely whether a verb with a physical reading has been generalized so to opt also for mental readings.

6 Alternatively, one could consider the arguments of relational nouns and prepositions to bear semantic roles as well, which would have only little additional explanatory force. 
in lower position, and possessor 'raising' adds a possessor in either a higher or a lower position. All these operations introduce new semantic roles, simply by the fact that they add predicates with a further argument. Therefore, the notion of semantic role is not necessary for capturing the resulting grammatical effects. More explanative is the notion of argument hierarchy because in terms of argument linking it is more important whether the additional argument is a higher or lower argument. Some of the involved operations may alternatively be characterized by an eventive role; for instance, causatives add a causing event, while resultatives add a resulting state.

Problematic is the fact that verb-verb compounds (and possibly also serial verb constructions and control structures) would need a device that selects between the roles that are similar in the two verbs. Mostly, however, the decision of which arguments have to be shared it made either on structural grounds or in a broader perspective semantically.

Most problematic is the fact that complex predicates often show systematic gaps which cannot be motivated by referring to semantic or eventive roles. I will address this issue in the next section.

\section{Argument hierarchy and structural arguments}

In all the above mentioned operations forming complex predicates the concept of argument hierarchy is most promising: either a higher or a lower predicate is added and licenses a further argument. In these operations, lexical decomposition is often prompted by overt morphology. Other instances, lacking overt morphology, but with similar morphosyntactic effects, as well as similar semantic readings, can be framed similarly. There is good reason to assume lexical decomposition also for basic ditransitive verbs, in the way suggested above. Given lexical decomposition of complex predicates, argument hierarchy can be predicted.

There is, however, one question in this context that must be answered: Why are certain arguments of a complex predicate blocked from realization? Neither semantic roles nor sortal factors can succesfully explain why this does happen. Consider the resultatives in (18). Both the intransitive verb + adjective combination and the transitive verb + adjective combination project on a 2-place construction, in which the result object (not selected by the verb) is preferred over the object of the base predicate (if transitive). In the semantic representation, the result predicate must be lower than the cause predicate, as required from a universal COHERENCE postulate (Kaufmann \& Wunderlich 1998).

(18) Strong resultatives

a. The joggers run their shoes threadbare.

$\lambda z \lambda x\{\operatorname{RUN}(\mathrm{x}) \&$ BECOME THREADBARE$(\mathrm{z})\}$

b. The guests drank the wine cellar empty. $\lambda z \lambda x\{\operatorname{DRINK}(\mathrm{x}, \mathrm{y}) \& \operatorname{BECOME} \operatorname{EMPTY}(\mathrm{z})\}$

In (18b), the substance being drunk (y) cannot be realized structurally because $\mathrm{y}$ is in a 'wrong' structural position, as I will argue. There is no good semantic explanation why y is blocked from realization, in particular if dative is available for a medial argument. In the locative alternation shown in (19) the locatum argument (y) can be human, but is at best realized obliquely (with the preposition mit 'with') rather than by structural case. 
(19) Locative alternation

a. Sie setzte ihre Verwandten in die erste Reihe.

'She placed her relatives in the first row.'

$\lambda P \lambda y \lambda x\{\operatorname{SET}(\mathrm{x}, \mathrm{y}) \& \mathrm{P}(\mathrm{y})\}$

b. Sie besetzte die erste Reihe mit ihren Verwandten.

'She occupied the first row with her relatives.'

$\lambda \mathrm{z} \lambda \mathrm{x}\{\operatorname{SET}(\mathrm{x}, \mathbf{y}) \&$ BECOME LOCATED $(\mathbf{y}, \mathrm{AT} z)\}$

Likewise, if a prefix or particle is added, the object (y) selected by the verb must not be expressed, even if it is human (20). Note that the prefix er-and the particle an essentially add the same semantic contribution; here, the resulting argument structure is canonically ditransitive.

(20) Prefix and particle verbs
a. Sie erküßte sich
den Partypreis.
she er-kissed herself.DAT the.ACC party prize
'She won the party prize through her kissing (people).'
b. Sie küßte sich einen Schnupfen an.
she kissed herself.DAT a.ACC cold at
'She got a cold through her kissing (people).'
$\lambda \mathrm{z} \lambda \mathrm{u} \lambda \mathrm{x}\{\operatorname{KISS}(\mathrm{x}, \mathrm{y}) \& \operatorname{BECOME} \operatorname{POSS}(\mathrm{u}, \mathrm{z})\}$

An even more puzzling example is given in (21); here, both the object and the directional complement of stellen are suppressed.

(21) Markus stellte den Keller (mit Möbeln) voll.

Markus put the cellar (with furniture) full

'Markus put (so many things into the cellar) that (as a result) the cellar got full.'

The directional complement obviously competes with another result predicate (voll in this case). The following constraint explains why only one of these result predicates can be expressed.

(22) PRedicAtive Arguments. A predicate variable must occupy the lowest position in the semantic form. (Hence, there can be only one at the time.) (Wunderlich 2000a)

We have still to explain the occurrence of object gaps. If one shifts from semantic roles to eventive roles (such as CAUSE and RESULT), associated with the predicates involved rather than with their arguments, one could state that arguments of a result predicate take preference over those of a cause predicate. However, this explanation fails in examples with an ORIENTATION predicate added by the particle, illustrated in (23). Here, the object of the verb can again only be expressed obliquely.

(23) Er sang die Freundin mit Arien an.

he sang the girlfriend with arias at

'He sang arias to his girlfriend'

$\lambda \mathrm{z} \lambda \mathrm{x}\{\operatorname{SING}(\mathrm{x}, \mathbf{y}) \&$ DIRECTED.TOWARDS$(\mathrm{z})\}$

This suggests that the CAUSE-RESULT relationship as a possible semantic factor for suppressing arguments is generalized to other types of predicates. Hence, the crucial insight must be that objects of a first predicate are never structural arguments. 
Before formalizing this result, let us consider some interesting variation of verb-verb compounds in Japanese in which the first verb is transitive and the second intransitive. What is the resulting argument structure? First, there are resultative compounds that show a similar behavior as the resultative constructions considered above: the object of the first verb can only be expressed obliquely.

(24) Resultative verb-verb compounds in Japanese

Yumiko ga $\left\{{ }^{*}\right.$ wain o/ wain de $\}$ nomi-tubure-ta

Yumiko NOM $\left\{{ }^{*}\right.$ wine ACC/wine with $\}$ drink-collapse-PAST

'Yumiko drank herself unconscious (with wine).'

$\lambda \mathrm{x}\{\operatorname{drink}(\mathrm{x}, \mathrm{y}) \&$ collapse $(\mathrm{x})\}$

Second, there are resultative compounds, in which, unexpectedly, the agent of the first verb must be suppressed.

(25) Unexpressed agents in Japanese verb-verb compounds
a. suupu ga ni-tamat-ta
soup NOM boil (tr.)-be.packed-PAST
'The soup boiled down'
b. * Taroo ga suupu o ni-tamat-ta
* Taroo NOM soup acc boil (tr.)-be.packed-PAST
'Taro boiled the soup down'
$\lambda y\{$ boil $(\mathbf{x}, \mathrm{y}) \&$ become be.packed $(\mathrm{y})\}$

As in (24), the surface ordering of the verbs corresponds to the semantic ordering of the predicates. ICONICITY requires that cause precedes result in the morphosyntactic structure, and COHERENCE requires that CAUSE commands RESULT in the semantic form. However, Japanese is right-headed and thus subject to the following restriction.

(26) SUBJECT HEAD: The highest argument of a verb-verb compound must be identical with the highest argument of the morphological head (which is the second verb in Japanese). (Gamerschlag 2000)

The agent of (24) is identified with the result object, but the agent in (25) is not. This is why the agent cannot be expressed, according to SUBJECT HEAD. Surprisingly, in a manner compound both subject and object of the first verb (the nonhead predicate) can be expressed.

(27) Watasi wa tegami o sagasi-mawat-ta.

I TOP letter ACC search-go.around-PAST

'I looked around for the letter'

$\lambda y \lambda x\{$ go.around$(x) \& \operatorname{search}(x, y)\}$

The ordering of the two verbs is subject to a constraint which is similar to ICONICITY; it requires that manner precedes path. However, there is no such constraint as COHERENCE at work here, and therefore the ordering of the predicates in the semantic form follows the default requirement: the head predicate $(\mathrm{PATH})$ commands the non-head predicate (MANNER). Given then the semantic form in the last line of (27), nothing prevents both $\mathrm{x}$ and y to be expressed structurally.

These three instances of Japanese transitive-intransitive compounds illustrated three different possibilities: one in which an object gap occurs, another one in which a subject gap occurs, and a third one in which both subject and object are expressed. The choice 
between these options is determined by two factors: (i) which argument of the first verb is identified with the argument of the second verb (which in turn depends on sortal possibilities); (ii) whether there is a specific condition for composing the semantic form (which in turn depends on the eventive roles involved): a cause predicate must command the result predicate, but no such condition holds if a manner predicate is involved. Under the theory advocated here, these two choices suffice to predict the resulting argument structure of the compound (Gamerschlag 2003).

With respect to the architecture of grammar, some more general remarks have to be added here. First, semantic form (SF) is considered a minimal semantic representation that allows us to predict the grammatical behaviour of a verb. More precisely, SF is a structured tree whose nodes represent logical types rather than grammatical categories, as will be illustrated below. Therefore, given two verbs that form a complex predicate, both the complex SF and the morphosyntactic realization have to be determined. And it is possible to derive from SF information about argument hierarchy. More details of this framework of Lexical Decomposition Grammar (LDG) have been worked out in Wunderlich (1997a, 1997b, 2000a).

Second, semantic notions play a role in order to determine which argument is the higher or the lower one of a basic transitive predicate (for instance, agents are higher than nonagents, possessors are higher than the possessed), as well as which predicate is the higher or the lower one in a complex predicate (for instance, causes are higher than results). These circumstances reflect the internal dynamics of an event: only agents can instigate and control an event, and causes may appear temporally earlier than results. ${ }^{7}$ Apparently, only very few semantic notions are necessary to determine the relative rank of both the arguments and the predicates in SF.

Third, given SF, argument hierarchy is a purely structural notion. All argument-shifting operations (causativization, applicative, possessor extension, locative alternation, prefixation, VV compounding, etc), be they morphosyntactically covert or not, yield SF structures which entail an argument hierarchy, and therefore also determine how the arguments are to be realized under the given morphosyntactic profile of the language. Thus, the level of SF is a rather robust generalization of grammar that allows the speakers to refrain from all particular semantic knowledge. (But have in mind that there are also possible places where further semantic knowledge may enter.)

The question now is how argument hierarchy derives from SF. The answer consists of two parts. DEPTH OF EMBEDDING (first proposed by Bierwisch 1989) yields a relative ordering of arguments; however, it is not clear whether first all arguments of a first predicate or first the highest arguments of all the involved predicates have to be considered. Therefore, a further restriction is needed that guarantees a unique solution. For this reason, the notion of L(exical)-command has been invented (Wunderlich 1997a,b), defined for the nodes in SF representing logical types. On the basis of this notion, STRUCTURAL ARGUMENT picks out a unique path from the highest to the lowest argument of a complex predicate: of every predicate except the lowest one only the highest argument is selected.

7 It is interesting to note that static relational predicates often appear in converse pairs, such as son-father, under-above, whereas dynamic predicates mostly do not. 
(28) Argument hierarchy

a. DEPTH OF EMBEDDING. Argument roles are abstracted over according to their relative ranking: the deeper an argument role is embedded in SF, the lower [i.e. more to the left] is its position in the list of abstractors.

b. STRUCTURAL ARGUMENT. An argument is structural only if it is either the lowest argument or (each of its occurrences) L-commands the lowest argument. [Hence, every non-highest argument of a nonfinal predicate in SF is nonstructural.]

c. L-command is defined as follows: $\alpha$ L-commands $\beta$ if the node $\gamma$, which either directly dominates $\alpha$ or dominates $\alpha$ via a chain of nodes type-identical with $\gamma$, also dominates $\beta$.

These notions are illustrated in the tree (29) with three arbitrary relational predicates A, B, and C. Only $\mathrm{x}, \mathrm{u}$ and $\mathrm{w} \mathrm{L}$-command the lowest argument $\mathrm{z}$; thus, only these four arguments are structural, and their ordering $\mathrm{x}>\mathrm{u}>\mathrm{w}>\mathrm{z}$ is reflected in the list of $\lambda$-abstractors (the thetaroles). In contrast, the arguments $\mathrm{y}$ and $\mathrm{v}$ are nonstructural; they may be identified with other arguments, or gapped (left implicit), or marked by explicit addressing their semantic role (i.e. obliquely).

Illustration of STRUCTURAL ARGUMENT

$\lambda \mathrm{z} \lambda \mathrm{w} \lambda \mathrm{u} \lambda \mathrm{x}\{\mathrm{A}(\mathrm{x}, \mathrm{y}) \& \mathrm{~B}(\mathrm{u}, \mathrm{v}) \& \mathrm{C}(\mathrm{w}, \mathrm{z})\}$

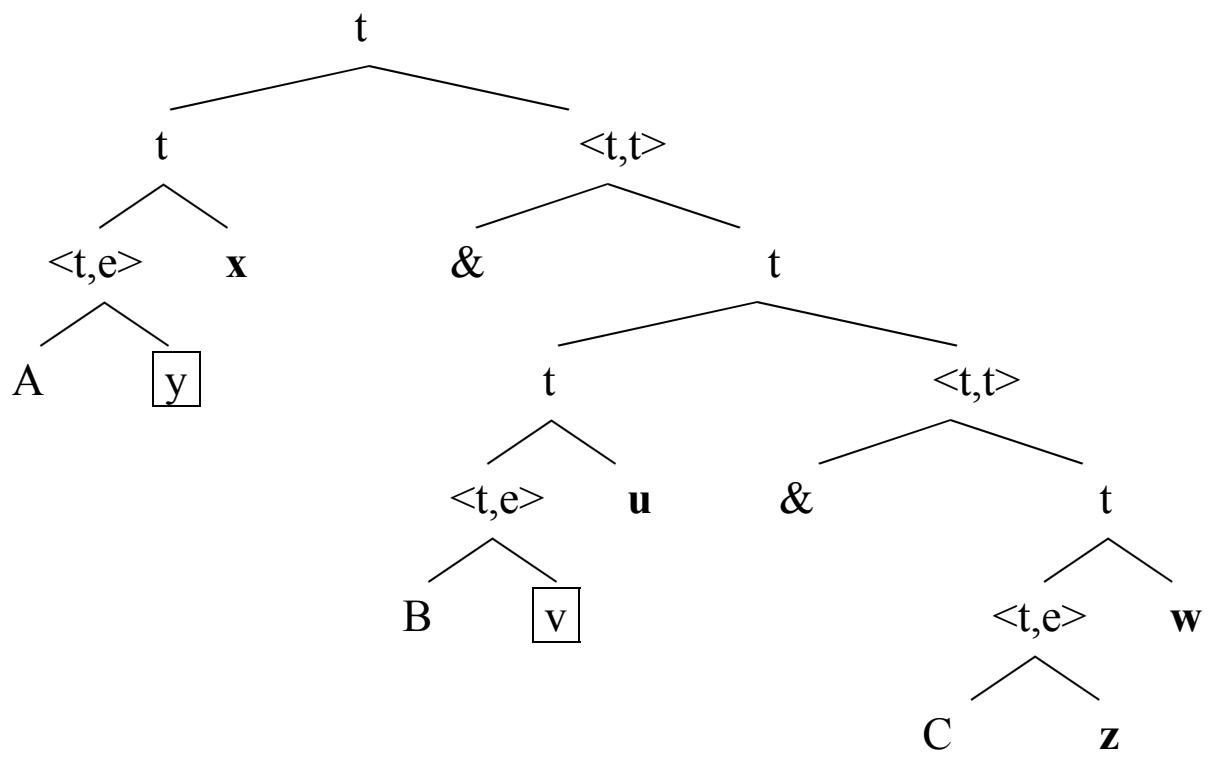

This mechanism is an optimal compromise between economy and expressivity. It is economical in reducing the number of possible structural arguments, and it is expressive in that every predicate is represented by an argument. Moreover, the special function of the lowest argument is respected: only this argument can be incorporated.

Given the sequence $\lambda z \lambda w \lambda u \lambda x$, there is a simple system that encodes each role by just two relative features, thereby also serving the purpose of morphological markedness: [+hr] for 'there is a higher role', and $[+1 \mathrm{lr}]$ for 'there is a lower role'. ${ }^{8}$ With the respective case specifications in (31) the case assignments attributed to the argument roles in (30) turn out to be optimal, hence canonical.

8 Similar features were invented by Kiparsky (1992), but failed for markedness considerations. 
(30) Featural encoding of the argument hierarchy

(31) Structural cases:

$$
\begin{array}{llllll}
\text { lowest } & \lambda \mathrm{z} & \lambda \mathrm{w} & \lambda \mathrm{u} & \lambda \mathrm{x} & \text { highest } \\
& +\mathrm{hr} & +\mathrm{hr} & +\mathrm{hr} & -\mathrm{hr} & \\
& -\mathrm{lr} & +\mathrm{lr} & +\mathrm{lr} & +\mathrm{lr} & \\
\text { ACC } & \text { DAT } & \text { DAT } & \text { NOM } & \text { accusative system } \\
\text { NOM } & \text { DAT } & \text { DAT } & \text { ERG } & \text { ergative system }
\end{array}
$$

$$
\begin{array}{ll}
\text { DAT } & {[+\mathrm{hr},+\mathrm{lr}]} \\
\text { ACC } & {[+\mathrm{hr}]} \\
\text { ERG } & {[+\mathrm{lr}]} \\
\text { NOM } & {[\mathrm{]}}
\end{array}
$$

ERG is optimal for the highest argument, and ACC for the lowest argument, while all medial arguments are best realized by DAT. The choice of NOM follows from the requirement that an unmarked case is preferred (DEFAULT). Furthermore, UNIQUENESS forbids the occurrence of a particular case more than once.

Note that there is a general asymmetry involved: it is better to mark a lower argument than a higher one (Stiebels 2000, 2002).

$$
[+\mathrm{hr}]>[+\mathrm{lr}]
$$

The higher argument is more prominent for raising and control structures, as well as for topicalization, and therefore should be unmarked. This is the reason why crosslinguistically, ergative systems are much rarer than accusative systems, and why ergative morphology can be coexistent with accusative syntax.

The two features [+hr] and [+lr] encode a sequence of theta roles from its two endpoints, the lowest or the highest role. There is an alternative for encoding a sequence of roles, namely by just one feature recursively.

$$
\begin{array}{llll}
\lambda \mathrm{z} & \lambda \mathrm{w} & \lambda \mathrm{u} & \lambda \mathrm{x} \\
+\mathrm{hr} & +\mathrm{hr} & +\mathrm{hr} & -\mathrm{hr} \\
+\mathrm{hr} & +\mathrm{hr} & -\mathrm{hr} & \\
+\mathrm{hr} & -\mathrm{hr} & &
\end{array}
$$

Since the morphological combination of $[+\mathrm{hr}]$ and $[-\mathrm{hr}]$ features is destructive, morphological cases that adapt to such an encoding cannot exist. However, the ordering expressed in (33) can be mapped onto the linear order of syntactic arguments, which seems to be the default option for all languages. Positional linking systems with SVO, where only the highest argument precedes the verb (as exemplified in the Bantu languages), mostly realize the next-to-highest argument (u), for instance, the recipient, as the 'primary object'. All the other objects ( $\mathrm{w}$, and $\mathrm{z}$ ) have to follow the primary object. In positional linking systems the perspective of the lowest argument, characterized by the feature [-1r], does not play any role. There are also morphological systems in which the recipient gets priority for object marking and passiviziation. 
4. Structural case in the context of semantic factors

Categorial generalization could be the major feature of the human language capacity. ${ }^{9}$ Once a category is introduced, it is better to follow the category than semantic classifications. For each category there are 'prototypical' instances, which are semantically defined and thus allow the language learner to acquire the category. In the course of generalization semantic factors become increasingly downgraded: once you have a category apply it for all instances. However, semantic factors remain present both as content and context. For the sake of semantic expressivity, categories may be relativized for some semantic factor. Theoretically, this can be done in two different ways, by marking the lexical item itself ('this is an exception'), or by marking the context ('this is an instance of an unusual context'). Therefore, one expects two kinds of reaction if a grammar has adapted a structural concept such as 'argument hierarchy determines the realization by case'.

The question is: How can structural case patterns become sensitive for semantic factors? Typological inspection reveals that indeed two reactions appear again and again, in nonrelated languages: (i) Semantic roles that differ from prototypical agents or patients are signalled by an additional lexical specification, which leads to either a noncanonical case pattern (such as 'experiencer dative') or to a pseudo-role (to be realized by expletives or inherent reflexives). Of course, lexical marking of this kind can become historically opaque.

(ii) The marked cases, bearing some processing load, are reserved for sortal values that are 'untypical' for an argument, while arguments with 'typical' values are realized by a less specified case (usually nominative). This phenomenon has been called 'differential object (or subject) marking'.

Lexical marking by a case feature leads to a noncanonical case pattern by which the respective class of verbs can be identified. This is exemplified by two examples from German. The feature $[+1 \mathrm{lr}]$ invites the inference that a proto-agent property is present ('an argument that exerts some control by itself'), and the feature [+hr] invites the inference that a proto-patient property is present ('an argument that is somehow affected'). Together with the respective default feature for a lower or a higher argument, in both instances a feature combination is achieved for which dative is optimal. Therefore, any attempt to capture an exceptional dative by just one semantic role must fail under this approach.

a. Sie folgte ihm.

She.NOM followed he.DAT

$\begin{array}{llll}\text { b. } & \lambda y & \lambda x & \operatorname{FOLLOW}(\mathrm{x}, \mathrm{y}) \\ \text { lexically } & +\mathrm{lr} & & \\ \text { default } & +\mathrm{hr} & & \\ & \text { DAT } & & \end{array}$

(35) a. Ihr gefiel er.

She.DAT liked he.NOM

9 Some researchers believe that recursivity is the major feature, possibly adapted from other systems (such as numbering, spatial navigation, or social relationships) (Hauser, Chomsky and Fitch 2002). Categorial generalization is necessary in order to deal with an increasing vocabulary in economic ways. Once the categories noun and verb and the possibility to convert verbs into nouns have been invented, at least one way of recursion is straightforward. Thus, categorial generalization may have prepared the possibility to invent recursion (Wunderlich 2002). 
b.

$\begin{array}{llll} & \lambda y & \lambda x & \operatorname{LIKE}(\mathrm{x}, \mathrm{y}) \\ \text { lexically } & & +\mathrm{hr} & \\ \text { default } & & +\mathrm{lr} & \end{array}$

DAT

Lexical marking by a pseudo-role preserves the canonical pattern. A pseudo-role in the highest position (an expletive argument) virtually lowers the true argument, and thus invites the same inference as the feature $[+\mathrm{hr}]$ does ('is affected'). In contrast, a pseudo-role in a non-highest position (a reflexive argument) virtually raises the true argument, and thus invites the same inference as the feature [+lr] does ('exerts control'). Although the examples, repeated from (15) above, can refer to the same state of affairs, they slightly differ in just this respect. If an actor played the scene, only (37) would be adequate, but if one wants to describe how someone actually reacted in the presence of spiders, the construction in (36) is preferred.
a. Ihn
ekelte
es
he.ACC disgusted it.NOM
'He was disgusted (at spiders).'
b. $\begin{array}{llll}\lambda z & \lambda x & \lambda y & \operatorname{DisGUST}(\mathrm{x}, \mathrm{z})\end{array}$
vor
ACC EXPL
a. Er ekelte sich (vor Spinnen).
he.NOM disgusted himself (at spiders)
'He was disgusted (at spiders).'
b. $\begin{array}{llll}\lambda \mathrm{z} & \lambda \mathrm{y} & \lambda \mathrm{x} & \operatorname{DISGUST}(\mathrm{x}, \mathrm{z})\end{array}$

REFL NOM

In turning to the second type of phenomena in which semantic issues interact with argument hierarchy, I remind the reader at the observation made in the beginning of this article: the higher argument tends to be more salient in terms of person, animacy and specificity than the lower argument. ${ }^{10}$ All these notions refer to sortal or referential values of the arguments, which they can have independent of their semantic role in the predicate. The argument linking system can be sensitive to these contextual values by a differential object or subject marking, i.e., by a split between marked and unmarked case.

The concept of harmonic alignment of scales (Prince and Smolensky 1993) can deal with such a phenomenon. Let us first consider a proposal made by Aissen (1999b, to appear). According to her account, harmonic alignment of the argument hierarchy in (38a) and one of the semantic scales in (38b) yields the preference scales in (38), to be read as 'local person subjects (i.e. 1st or 2 nd person) are preferred over 3rd person subjects' etc., while the reverse readings hold for objects. The reversal of these preference scales then gives the markedness hierarchies in (38), to be read as 'Avoiding 3rd person subjects is better than avoiding local person subjects'.

10 Other possible factors would be humanness and defineteness, as well as the nominal category (demonstrative, pronoun, full noun), and also number. 
(38) Harmonic alignment of scales (Aissen 1999b)

a. Argument hierarchy:

subject $(\mathrm{sb})>\operatorname{object}(\mathrm{ob})$

b. Contextual semantic scales:

person: $\quad$ loc $>3$

animacy: $\quad+$ anim $>-$ anim

specificity: + spec $>-$ spec

c. Harmonic alignments:

$\mathrm{sb} / \mathrm{loc}>\mathrm{sb} / 3 \quad \mathrm{ob} / 3 \quad>\mathrm{ob} / \mathrm{loc}$

$\mathrm{sb} /$ +anim $>\mathrm{sb} /$-anim $\quad \mathrm{ob} /-$ anim $>\mathrm{ob} /$ +anim

$\mathrm{sb} /+$ spec $>$ sb/-spec ob/-spec $>$ ob/+spec

d. Contextualized markedness hierarchies:

$\begin{array}{llll}* \text { sb/3 } & \text { " *sb/loc } & * \text { ob/3 } & \text { *ob/loc } \\ \text { *sb/-anim } & \text { *sb/+anim } & * \text { ob/+anim } & \text { *ob/-anim } \\ \text { *sb/-spec } & \text { "sb/+spec } & * \text { ob/+spec } & \text { *ob/-spec }\end{array}$

These markedness hierarchies can serve to describe of whether a given argument is preferably encoded as object (in an active clause) or as subject (in a passive clause), they do not imply anything about the choice between marked and unmarked case. ${ }^{11}$ The crucial insight for understanding the relationship between the harmonic alignments and morphological marking is the following (due to Comrie 1989, and Dixon 1994). Only arguments that deviate from what is expected are encoded by a marked case. 3rd person subjects are less expected than local person subjects, and local person objects are less expected than 3rd person objects; therefore only 3rd person subjects should be marked by ergative, and only local person objects should be marked by accusative. (Similarly for the other types of salience.)

This insight leads to the alternative proposal in (39). The relevant scale from which one has to start off is not the argument hierarchy but the ranking of morphological features in (39a), already mentioned in (32). The markedness hierarchies in (39c) now give the desired results: 'Avoiding ergative for local person is better than avoiding ergative for 3rd person', etc.

(39) Harmonic alignment in the presence of morphological factors (Stiebels 2000, 2002) ${ }^{12}$

a. Morphological features:

$[+\mathrm{hr}]>[+\mathrm{lr}] \quad(\mathrm{ACC}>\mathrm{ERG})$

('It is better to mark objects than subjects')

b. Contextual semantic scales:

person: $\quad$ loc $>3$

animacy: $\quad+$ anim $>-$ anim

specificity: + spec $>-$ spec

11 For this purpose, Aissen conjoins the markedness constraints with another type of markedness, namely whether the arguments are case-marked or not. This move is unnecessarily complex, and it does not pay regard to the distinction between ergative and accusative. As Stiebels (2003) shows, it also leads to wrong results.

12 For convenience, I use the case names ERG and ACC rather than the respective features, which would be more adequate in the general framework. 
c. Contextualized markedness hierarchies:

$$
\begin{aligned}
& \text { *ERG/loc »*ERG/3 * * } 3 \text { ACC/3 } / 3 \text { ACC/loc } \\
& \text { *ERG/+anim »*ERG/-anim * * }{ }^{*} \mathrm{ACC} / \text {-anim } * *_{\mathrm{ACC} /+ \text { anim }} \\
& \text { *ERG/+spec »*ERG/-spec *ACC/-spec "*ACC/+spec }
\end{aligned}
$$

On the basis of this result one expects possible effects in the lexical inventory of morphemes, as well as in the distribution of morphemes forming possible case patterns for a clause. The markedness constraints relate to economy; their effect is counterbalanced by faithfulness constraints relating to expressivity, such as $\operatorname{Max}(+\mathrm{hr})$ 'Realize the feature [+hr] by an accusative' and $\operatorname{Max}(+\mathrm{lr})$ 'Realize the feature [+lr] by an ergative'. These constraints can differently interpolate with the markedness hierarchies in (39c), thereby giving the individual languages their profile.

One of the expectations resulting from (39c) concerns the existence of languages that lack an ERG morpheme for local person, and also languages that lack an ACC morpheme for 3rd person. A typical instance of a language that meets both of these expectations is Yidin (Australian), which has an ergative set for 3rd person, and an accusative set for 1st and 2nd person. There is also an overlapping region II with human demonstratives, which show both an ergative and an accusative morpheme. Similar is Dyirbal, another Australian language, in this case without overlapping.

\begin{tabular}{|c|c|c|c|}
\hline \multirow[b]{2}{*}{ noun/adjective } & NOM & $\mathrm{ACC}$ & ERG \\
\hline & $\varnothing$ & - & $-n g u /-d u$ \\
\hline DEM: -def,-anim,+gen & wani & - & wani:ndu \\
\hline DEM : -def,-anim, + spez & wani:ra & 一 & wapirangu \\
\hline DEM: +def,+hum & yinu & yinfu:n & yinfu:y \\
\hline DEM: -def,+hum & wana & wanfu:n & wajfu \\
\hline $1 \mathrm{SG}$ & yayu & yanan & - \\
\hline $1 \mathrm{DU}$ & yali & yali:n & - \\
\hline 1PL & парғi & yanji:n & - \\
\hline $2 \mathrm{SG}$ & nundu & junin & - \\
\hline 2PL & nund:ba & nundu:ban & - \\
\hline
\end{tabular}

Gaps in the linker inventory of Yidin (Dixon 1977)

\begin{tabular}{|c|c|c|c|}
\hline & NOM & $\mathrm{ACC}$ & ERG \\
\hline $\begin{array}{l}\text { noun } \\
\text { DEM: F.SG } \\
\text { DEM: M.SG }\end{array}$ & $\begin{array}{c}\varnothing \\
\text { balan } \\
\text { bayi }\end{array}$ & - & $\begin{array}{c}\text {-ngu } \\
\text { baygun } \\
\text { baygul }\end{array}$ \\
\hline $\begin{array}{l}\text { 1PL 'we all' } \\
\text { 2PL 'you all' }\end{array}$ & $\begin{array}{l}\text { yana } \\
\text { nurra }\end{array}$ & $\begin{array}{c}\text { yana-na } \\
\text { nurra-na }\end{array}$ & - \\
\hline
\end{tabular}

(41) Gaps in the linker inventory of Dyirbal (incomplete; Dixon 1994:10/14)

The two constraint hierarchies that account for these inventory gaps (leaving out the overlapping region in Yidin) are the following. 

a. ${ }^{*} \mathrm{ERG} / \mathrm{loc} \gg \operatorname{Max}(+\mathrm{lr}) \gg{ }^{*} \mathrm{ERG} / 3$
b. ${ }^{*} \mathrm{ACC} / 3 \gg \operatorname{Max}(+\mathrm{hr}) » *^{*} \mathrm{ACC} / \mathrm{loc}$

Of course, other languages may have other rankings. In particular, there may be rankings such as those concerning specificity that do not induce gaps in the inventory of morphemes but rather in the realization of nominal arguments, i.e. in the distribution of case patterns for nominal arguments. The rankings in (42) give rise to four types of case patterns which exhibit the involved ergative and accusative splits.

(43) Four possible case patterns

\begin{tabular}{|l|l|}
\hline $\begin{array}{l}\text { Direct setting (loc/3) } \\
\text { 'We see the man.' } \\
\text { NOM NOM }\end{array}$ & $\begin{array}{l}\text { Inverse setting (3/loc) } \\
\text { 'The man sees us.' } \\
\text { ERG ACC A A }\end{array}$ \\
\hline $\begin{array}{l}\text { Symmetric setting (loc/loc) } \\
\text { 'The man sees him.' }\end{array}$ & $\begin{array}{l}\text { Symmetric setting (3/3) } \\
\text { 'The man sees him.' } \\
\text { NOM ACC }\end{array}$ \\
\hline
\end{tabular}

In summarizing, the interaction of argument hierarchy with semantic factors yields certain types of noncanonical or underspecified case patterns. Semantic roles are accounted for by additional features (a relational device) that replace the default features as shown in the lower part of figure (44). 'Typical' sortal (or referential) values are accounted for by blocking the positive features (a purely local device), so that a less specific realization results.

(44) Two ways in which semantic factors can interact with argument hierarchy

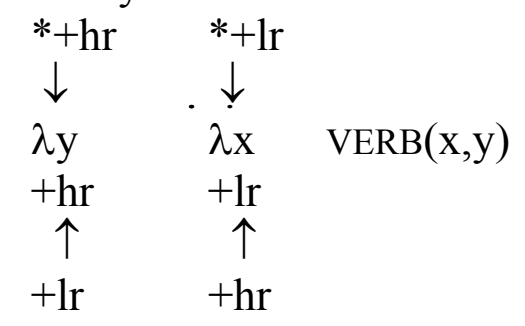

These four possibilities can coexist in a language. This is illustrated with data from two unrelated languages: Udi, a Northeast Caucasian language, and Hindi. Only the conditions under which an ergative split appears differ in these languages. Moreover, the formal means are slightly different. The Udi accusative (traditionally called 'dative2') is derived by the suffix /- $\mathrm{x} /$ from the dative (this is one of the rare cases in which the accusative is morphologically more marked than the dative), whereas in Hindi accusative and dative have been syncretisized. Nevertheless, the general profile of splits is identical in these two languages. 
Four types of split in Udi (NE Caucasian)

\begin{tabular}{|l|l|l|}
\hline $\begin{array}{l}\text { Ergative split in the } \\
\text { inventory }\end{array}$ & $\begin{array}{l}\text { There are no ergative 1st and 2nd } \\
\text { person pronouns. }\end{array}$ & $\begin{array}{l}\text { Markedness: } \\
\text { *[+lr]/local person }\end{array}$ \\
\hline Salience split & $\begin{array}{l}\text { In transitive verbs, accusative } \\
\text { alternates with nominative. } \\
\text { Accusative only occurs with definite, } \\
\text { animate or pronominal objects. }\end{array}$ & $\begin{array}{l}\text { Markedness: } \\
\text { *[+hr]/low salience }\end{array}$ \\
\hline Intentionality split & $\begin{array}{l}\text { Intransitive verbs encode intentional } \\
\text { body actions ('those that are thought } \\
\text { to be controlled') by ergative rather } \\
\text { than nominative. }\end{array}$ & $\begin{array}{l}\text { Lexical feature: }[+ \text { lr }] \\
\text { ('controller') }\end{array}$ \\
\hline Experiencer split & $\begin{array}{l}\text { In transitive verbs, ergative } \\
\text { alternates with dative. Dative occurs } \\
\text { with perception verbs, but also with } \\
\text { other kinds of verbs (exceptionally } \\
\text { marked). }\end{array}$ & $\begin{array}{l}\text { Lexical feature: }[+ \text { hr }] \\
\text { ('affected') }\end{array}$ \\
\hline
\end{tabular}

The examples below illustrate these statements (Schulze 2001). ${ }^{13}$ (46) shows both the lack of an ergative form of the 1st person and the definiteness effect with objects. (47) shows an intransitive verb that assigns ergative under specific conditions. $(48 \mathrm{a}, \mathrm{b})$ show different choices of subject marking: be?g/ 'see' with agentive reading selects ergative, while ak' 'see' with experiencer reading selects dative; in addition, (48c) attests that the object variation between nominative/accusative is independent of the case of the subject. The examples also show that subject agreement on the verb is either nominative or dative.

(46) Ergative and accusative split in Udi
a. $\mathrm{zu}$ s/um / s/um-ax
I.NOM bread.NOM / bread-ACC 'I eat bread/the bread.'
b. $\mathrm{s}^{\wedge} \mathrm{e}-\mathrm{t}^{\prime}$-in s/um / s/um-ax DIST-t'-ERG bread.NOM / bread-ACC '(S)he eats bread/the bread.'

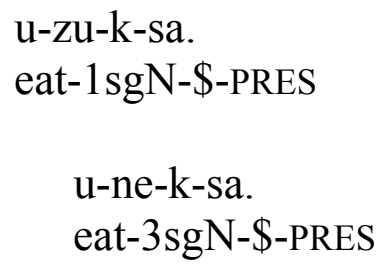

(47) Intentionality split in Udi

a. xinär axs/um-ne-xa. girl laugh-3sgN-LV.PRES

'The girl is laughing.'

b. xinär-en gölö axs/um-ne-xa. girl-ERG much laugh-3sgN-LV.PRES

'The girl is laughing very much.'

13 Both $/ \mathrm{t}$ / and $/ \mathrm{n} /$ which precede the case ending are stem augments. The subject marker on the verb is infixed, with ' $\$$ ' being part of the stem. -xa is a present allomorph, formed from the light verb pesun 'say'. 
(48) Experiencer split in Udi
a. gädi-n-en sa adamar be?-ne-g/-i.
boy-n-ERG one man.NOM see-3sgN-\$-AOR
'The boy saw (observed) a man.'
b. gädi-n-a sa adamar a-t'u-k-i.
boy-n-DAT one man.NOM see-3sgD-\$-AOR
'The boy saw (perceived) a man.'
c. gädi-n-a adamar-ax a-t'u-k-i
boy-n-DAT man-ACC see-3sgD-\$-AOR
'The boy saw the man.'

As already mentioned, Hindi exhibits the same types of case split as Udi, with only slightly different conditions.

Four types of split in Hindi

\begin{tabular}{|l|l|l|}
\hline $\begin{array}{l}\text { Ergative split is } \\
\text { aspectually } \\
\text { conditioned }\end{array}$ & $\begin{array}{l}\text { Ergative is restricted to perfective } \\
\text { forms. }\end{array}$ & $\begin{array}{l}\text { Markedness: } \\
*[+\mathrm{lr}] /- \text { perf }\end{array}$ \\
\hline Salience split & $\begin{array}{l}\text { In transitive verbs, accusative only } \\
\text { occurs with human, specific-animate } \\
\text { or definite-inanimate objects. }\end{array}$ & $\begin{array}{l}\text { Markedness: } \\
*[+ \text { hr]/low salience }\end{array}$ \\
\hline Intentionality split & $\begin{array}{l}\text { Some intransitive verbs alternate } \\
\text { between ergative and nominative } \\
\text { depending on whether the action is } \\
\text { deliberately done or not. }\end{array}$ & $\begin{array}{l}\text { Lexical feature: }[+ \text { lr }] \\
\text { ('controller') }\end{array}$ \\
\hline Experiencer split & $\begin{array}{l}\text { Transitive experiencer verbs (e.g. } \\
\text { perception verbs) encode their } \\
\text { subject with accusative. (Note that } \\
\text { Hindi exhibits accusative-dative } \\
\text { syncretism.) }\end{array}$ & $\begin{array}{l}\text { Lexical feature: }[+h r] \\
\text { ('affected') }\end{array}$ \\
\hline
\end{tabular}

The following examples, taken from Mohanan (1994), illustrate these statements. Both (50) and (51) show that the subject is marked by ergative in the perfect, but not in the future. In addition, (50) shows that for human objects, always marked by accusative, it is undetermined whether they get a definite or an indefinite reading, whereas inanimate objects in the nominative only get an indefinite reading, as shown in (51). These examples also illustrate four types of agreement behaviour: no agreement in (50a), agreement with the subject in (50b), agreement with the object in (51a), and agreement with the subject in the presence of another nominative argument, in (51b).

(50) Ergative split in Hindi, human object

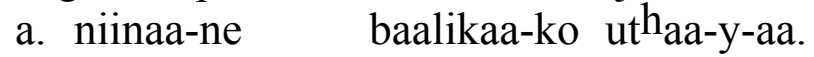
Nina.F-ERG girl-ACC lift-PERF-M
'Nina lifted up a/the girl.'
Nina.F.NOM girl-ACC lift-FUT-F
'Nina will lift up a/the girl.'
b. niinaa baalikaa-ko ut $\mathrm{h}_{\mathrm{aa}-\mathrm{eg} \text {-ii. }}$ 
(51) Ergative split in Hindi, inanimate object
a. niinaa-ne roTii khaa-y-ii.
Nina.F-ERG bread.F.NOM eat-PERF-F
'Nina ate bread.'
b. niinaa kelaa khaa-eg-ii.
Nina.F.NOM banana.M.NOM eat-FUT-F
'Nina will eat a banana.'

Hindi has a couple of intransitive verbs (such as cillaa 'shout', naac 'dance'), which alternate between ergative and nominative subjects, depending on whether the action is deliberatively done or not, whereas a few intransitive verbs (nahaa 'bathe', $c^{h} \tilde{l} i k$ 'sneeze') take ergative subjects only; they are lexically marked with the feature [+lr]. Lexical marking with the feature $[+\mathrm{hr}]$ is shown in (52).

$$
\begin{aligned}
& \text { Experiencer split in Hindi } \\
& \text { tusaar-ko caand } \text { dik }^{\mathrm{h}} \text {-aa. } \\
& \text { Tushar-ACC moon.M.NOM see-PERF-M } \\
& \text { 'Tushar saw the moon' }
\end{aligned}
$$$$
\text { (Mohanan 1994:141) }
$$

Recall that Hindi does not have an overt dative, and thus shows ACC-DAT syncretism. In the tradition of Hindi grammar it is assumed that the postnominal clitic $-k o$ is ambiguous between dative and accusative, a position that is defended by Mohanan (1994) and Butt (1995). One of their arguments is that in all constructions where dative is expected, in experiencer subject constructions such as those in (52) and in ditransitive verbs with a medial argument, any salience split is lacking. As the examples in (53) show, the medial argument of ditransitive verbs is always realized by $-k o$, and their lowest argument by the unmarked nominative.
Ditransitive verbs in Hindi
a. Ravii-ne baalak-ko/*baalak Ravi-ERG boy-ACC/boy.NOM child.NOM/*child-ACC 'Ravi gave a/the child to a/the boy.'
b. Ravii-ne gaay-ko/*gaay
Ravi-ERG cow-ACC/cow.NOM banana.NOM/*banana-ACC
'Ravi fed a/the cow a/the banana.'
kelaa/*kele-ko
banana.NOM/*banana-ACC eat.CAUS.PERF-M

Let us nevertheless assume that $-k o$ is simply an accusative morpheme. The realization of $-k o$ is independent of animacy or definiteness just in those contexts in which the underlying role specification is $[+\mathrm{hr},+\mathrm{lr}]$. The highest argument of the experiencer verbs, which is $[+\mathrm{lr}]$ inherently, is lexically marked for [+hr], and the medial argument of ditransitive verbs is $[+\mathrm{hr},+\mathrm{lr}]$ inherently. It is the existence of the feature [+lr], which blocks the possibility of a salience split regarding [+hr]. The feature combination $[+\mathrm{hr},+\mathrm{lr}]$ must always be expressed by maximal means, which is dative if it is available, otherwise accusative. Neither can the lowest argument alternate between accusative and nominative, because UNIQUENESS ('No marked case should appear more than once in a pattern') forbids a second accusative. The constraints assumed in the analysis by Wunderlich (2000b) successfully explain why not every $[+\mathrm{hr}]$ argument underlies the accusative-nominative split.

As illustrated above, Udi and Hindi have a quite similar structural case system, with the same types of alternations reflecting semantic factors. In contrast, their agreement systems are relatively poor and exclusively structural; here, Udi and Hindi choose different options. 
The Udi verb always agrees with the highest argument, regardless of whether it is nominative or ergative; and there are special agreement markers with dative subjects, which are lexically marked. The latter fact shows that agreement still plays some role in the argument linking system of Udi. In contrast, the Hindi verb only agrees with a nominative argument, and in case of double nominative with the higher argument. If no nominative is present, the verb takes the default form mask.sg. The agreement features are reduced to gender and number. Evidently, agreement does not take any part in the argument linking system of Hindi, it has at best discriminative function.

Agreement in Udi vs. Hindi

\begin{tabular}{|c|c|c|c|}
\hline $\begin{array}{l}\text { Udi: the verb agrees with the } \\
\text { highest argument }\end{array}$ & $\begin{array}{l}\text { Hindi: the verb agrees with the } \\
\text { highest nominative argument }\end{array}$ \\
\hline agr.N - NOM & & agr - NOM & \\
\hline agr.N - ERG & & ERG & \\
\hline agr.N - ERG & NOM/ACC & ERG & agr - NOM \\
\hline & & ERG & ACC \\
\hline agr.N - NOM & NOM/ACC & agr - NOM & NOM/ACC \\
\hline agr.D - DAT & NOM/ACC & ACC & agr - NOM \\
\hline
\end{tabular}

Although the agreement systems of the languages considered here do not much contribute to argument linking, the impression that this would generally hold is certainly wrong. Many languages display a so-called head-marking, in which the argument structure of a verb is indicated by pronominal affixes attached to the verb. The structural properties of these headmarking systems are often very similar to those of dependent-marking systems, which attribute morphological case to syntactic arguments. The different sets of pronominal affixes often can be described by the same notions as used for morphological case: dative, ergative, accusative, and nominative. The notion of generalized case can serve to subsume the common properties of morphological case and pronominal affixes. Both the claim that argument hierarchy is the crucial factor of argument linking and the claim that there are only two ways in which semantic factors can enter structural argument linking also hold for generalized case in general. That is, lexical marking for untypical argument roles, as well as differential object/subject marking in the context of salience factors, should be observed for pronominal affix systems as well, which indeed is true. <a language that marks experiencers pronominally, a language outside of Bantu that has differential object marking on the verb ??>

If head-marking looses its principal function for argument linking, it might be reduced to an agreement system which is relatively poor for argument linking, for instance, misses the pro-drop property. On the other side, if free pronouns are clustered to clitics associated with the verb (or an auxiliary), this may be the first step to a head-marking system. One should not expect that in these transitional systems alternatives develop that also reflect the semantic factors considered here. Pure agreement morphemes seem to be too poor to preserve semantic sensitivity, and pure clitics seem to be too structural to react to semantic factors. 


\section{Conclusions}

Among the languages of the world, generalized case, be it instantiated by morphological case or by pronominal affixation, is not only the most common but also the most effective type of argument linking. I argued that this is so because this type of argument linking widely abstracts from semantic factors and uses argument hierarchy as its central concept. Although in basic 2-place predicates argument hierarchy itself is determined semantically, in all complex or derived predicates it is uniquely determined by L-command, which reflects the structure in which basic predicates are combined. All arguments that do not Lcommand the lowest argument are blocked from structural realization.

I further argued that there is a small and closed set of structural cases defined by features of argument hierarchy, which guarantees a canonical case pattern for every intransitive, transitive or ditransitive verb. At the same time, this set of structural cases is flexible enough to form noncanonical case patterns under particular semantic conditions. Either an argument position of the hierarchy is specified by an additional feature (lexically), or the realization of its feature is made context-dependent. In other words, the particular argument is realized by a case which is more or less specific than in the canonical pattern. The former option concerns the underlying features and therefore can have global effects, whereas the latter option is always locally restricted.

It would not be adequate to describe the global effects as dependencies in a semantic sense; they always follow from two simple global constraints, namely DEFAULT ('Each case pattern should include nominative') and UNIQUENESS ('No case should appear more than once in a pattern') (Stiebels 2000, 2002, Wunderlich 2003), and mostly result in a less specified case for another argument. For instance, the feature [ $+\mathrm{hr}]$ for the higher argument turns the canonical pattern $<$ nom, acc $>$ into $<$ dat, nom $>$ rather than $<$ dat, acc $>$ because of DEFAULT. The requirement of UNIQUENESS may also trigger semantic case on one of the arguments, as is exemplified in ditransitive verbs in languages that lack dative (Wunderlich and Lakämper 2001).

In this paper, I did not consider positional argument linking, which, however can be captured by similar means. The syntactic ordering of arguments mostly follows the argument hierarchy, regardless of the position of the verb, except that some V-initial languages prefer VOS. This ordering is affected by the informational status of the arguments as topic or focus, but never by semantic factors. A strict SVO positional system is unable to react to the semantic factors considered here.

From the point of typology, thus three linguistic types emerge: (i) languages that do not have acquired the property of generalized case (always languages with a considerable amount of morphology, such as the Algonquian languages with inverse morphology), (ii) languages that do inhere the property of generalized case (languages that must have at least some amount of morphology), (iii) languages that lack any morphology in argument linking (languages that only use SVO positional linking). Languages of the first type use semantic factors for determining argument linking in various ways. Languages of the second type have achieved a structural argument linking system and take semantic factors only additionally to the structural system in just two ways (or three ways, if one includes the possibility of semantic case). Languages of the third type have lost any systematic way to react to semantic factors, they can only react to pragmatic factors.

Elaborating this view, one might find that these three linguistic types also characterize certain evolutionary stages. For 'early' languages the semantic factors are dominant. In the process of generalization, structural factors may become more important, leaving for 
semantic factors only some clearly structured ways. Having undergone a process of further generalization, 'late' languages ignore these semantic factors altogether, leaving pragmatic factors as the sole source for alternative argument linking.

\section{References}

Aissen, Judith. 1999a. Agent focus and inverse in Tzotzil. Language 75, 451-485.

Aissen, Judith. 1999b. Markedness and subject choice in Optimality Theory. Natural Language and Linguistic Theory 17, 673-711.

Aissen, Judith. To appear. Differential object marking: iconicity vs. economy. Natural Language and Linguistic Theory.

Butt, Miriam. 1995. The Structure of Complex Predicates in Urdu. Stanford: CSLI publications.

Comrie, Bernerad. 1989². Language universals and linguistic typology. Oxford: Blackwell.

Dowty, David. 1991. Thematic proto-roles and argument selection. Language 67, 547-619.

Dixon, R.M.W. 1994. Ergativity. Cambridge University Press.

Gamerschlag, Thomas. 2000. Deriving argument structure in Japanese V-V compounds. Working papers 'Theory of the lexicon' 114, University of Düsseldorf.

Gamerschlag, Thomas. 2003. Komposition, Köpfigkeit und Argumentstruktur komplexer Verben. Doctoral dissertation, University of Düsseldorf.

Hauser, Marc D., Noam Chomsky, and Tecumseh Fitch. 2002. The faculty of language: what is it, who has it, and how did it evolve? Science 298, 1569-1579.

Hockett, Charles F. 1948. Potowatomi III: The verb complex. International Journal of American Linguistics 14, 139-149.

Kallulli, Dalina. 1999. Non-active morphology in Albanian and event (de)composition. In Istvan Kenesei (ed.) Crossing Boundaries, 263-292. Amsterdam: John Benjamins.

Kaufmann, Ingrid and Dieter Wunderlich. 1998. Cross-linguistic patterns of resultatives. Working papers 'Theory of the lexicon' 109. Ubiversity of Düsseldorf.

Kimenyi, Alexandre. 1980. A relational grammar of Kinyarwanda. Berkeley: Univ. of California Press.

Kiparsky, Paul. 1992. Structural case. Ms., Institute for Advanced Study, Berlin.

Klein, Katarina and Silvia Kuscher. 2002. Psychic verbs and lexical economy. Working Papers 'Theory of the lexicon' 122. University of Düsseldorf.

Maling, Joan. 2001. The heterogeneity of the mapping among morphological case, grammatical functions, and thematic roles. Lingua 111, 419-464.

Maling, Joan. 2002. Icelandic verbs with dative objects. Working Papers in Scandinavian Syntax 70, 1-59. Department of Scandinavian Languages, Lund.

Mohanan, Tara. 1994. Argument structure in Hindi. Stanford: CSLI Publications.

Morimoto, Yukiko. 2002. Topic salience and cross-linguistic patterns of agreement (Bantu), Ms, Univ. Düsseldorf

Prince, Alan and Paul Smolensky. 1993. Optimality Theory: constraint interaction in generative grammar. Ms., Rutgers University, New Brunswick and University of Colorado, Boulder.

Schulze, Wolfgang. 2001. The Udi Language: A grammatical description. Online, Univ. München.[http://www.lrz-muenchen.de/ wschulze/]

Stiebels, Barbara. 2000. Linker inventories, linking splits and lexical economy. In Barbara Stiebels \& Dieter Wunderlich (eds.) Lexicon in Focus. Studia Grammatica 45. Berlin: Akademie Verlag, 211-245. 
Stiebels, Barbara. 2002. Typologie des Argumentlinkings: Ökonomie und Expressivität. Studia Grammatica 54. Berlin: Akademie Verlag.

Stiebels, Barbara. 2003. Agent focus in Mayan languages. Ms., Zentrum für Allgemeine Sprachwissenschaft (ZAS) Berlin.

Tallerman, Maggie. 1990. Relativisation strategies: NP accessability in Welsh. Journal of Linguistics 26, 291-314.

Van Valin, Robert D., Jr. 1993. A synopsis of Role and Reference Grammar. In R. Van Valin (ed.) Advances in Role and Reference Grammar. Amsterdam: John Benjamins, 1-164.

Wunderlich, Dieter. 1996. A minimalist model of inflectional morphology. In Chris Wilder, Manfred Bierwisch and Hans-Martin Gärtner (eds.) The Role of Economy Principles in Linguistic Theory. Berlin: Akademie Verlag, 267-298.

Wunderlich, Dieter. 1997a. Cause and the structure of verbs. Linguistic Inquiry 28, 27-68.

Wunderlich, Dieter. 1997b. Argument extension by lexical adjunction. Journal of Semantics 14, 95142.

Wunderlich, Dieter. 2000a. Predicate composition and argument extension as general options. In Barbara Stiebels \& Dieter Wunderlich (eds.) Lexicon in Focus. Berlin: Akademie Verlag, 247270.

Wunderlich, Dieter. 2000b. Optimal case in Hindi. Ms., Univ. Düsseldorf.

Wunderlich, Dieter. 2002. Major steps in the evolution of language. Ms, Univ. Düsseldorf.

Wunderlich, Dieter. 2003. Optimal case patterns: German and Icelandic compared. In Ellen Brandner and Heike Zinsmeister (eds.) New Perspectives on Case Theory. CSLI publications, 329-365.

Wunderlich, Dieter \& Renate Lakämper. 2001. On the interaction of structural and semantic case. Lingua 111, 377-418.

(home page: http://web.phil-fak.uni-duesseldorf.de/ wdl/) 